\title{
Research on Innovative Training Mode for Students Majoring in Mechanical Engineering
}

\author{
Ziyang $\mathrm{Cao}^{1, \mathrm{a}^{*}}$ and Guangxun Wang ${ }^{1, \mathrm{~b}}$ \\ ${ }^{1}$ College of Mechanical Engineering, Suzhou University of Science and Technology, \\ Suzhou, China \\ adukeczy@nuaa.edu.cn, boguangxun_77@163.com
}

\begin{abstract}
Keyword: Talent training model; Creative ability; Education system; Mechanical engineering.
\end{abstract}
\begin{abstract}
With the popularization of higher education transformation, a diversified educational situation is formed. Many colleges choose a different talent training mode for different types and levels, which have a clear orientation focusing on the characteristics of school. It is an important part of deepening the reform of higher education. During the process of deepening educational reform, the college of mechanical engineering of Suzhou University of Science and Technology actively explores the application of talents training, establishing the training model of "wide caliber, thick foundation, focus on ability and seek individuality". The model pays attention to the coordinated development of human knowledge, ability and quality based on knowledge-teaching and focused on the ability- foster. The models also focus on cultivating awareness of innovative application-oriented talents so that people have a strong practical, innovative ability and professional skills. After years of efforts, the structure of talent training model in mechanical engineering is innovated and some of the reform measures are practiced.
\end{abstract}

\section{Introduction}

Talents training is the fundamental task of universities, and the basic orientation of teaching reform is training high-quality applied innovative talents [1-3]. With the development of economy and technology, the impact and cross-cutting of multidisciplinary is deepening. The connotation of mechanical discipline has undergone many changes. Talent training model and quality in mechanical engineering faced with how to adapt to new developments and new demand issues [4].

The traditional cultivation mode of subject education is formed and implemented under the guidance of the cultivating future scientists during elite education [5-6]. In the popular education, the University is no longer a single elite education. Traditional faculty education and talents training mode does not apply to advanced engineering and technical personnel training objective of mechanical engineering in our university. Implementation of innovative talent training mode, you must shift from subject education to engineering education, shift from theory to practice, implement engineering education. With the knowledge of science and technology innovation as the driving force of economic growth [7-8], enterprises pay much attention to independent intellectual property rights and core technology, innovation. People as the subject of innovation, on the cultivation of college students ' ability of innovative high quality aspects put forward higher requirements. Talents mainly oriented to production line, position of the needs must possess the necessary professional knowledge and practice skills. Traditional implementations, experiments, curriculum design, practice, practice for the respective course service, theory and practice are fragmented and lack of project link, verifiability-oriented practice teaching requirements, cannot effectively foster students' ability of engineering practice and innovation.

The key of implementation of innovative talent training mode lies in the pattern of the top level design and all-round building talent growth environment of the specific measures to implement [910]. At present, the application of innovative talent training model in mechanical engineering is in the exploration stage, and students' practice ability and innovative consciousness are still weak, implementing creative education and yet recognized a fundamental breakthrough. Creative personnel training is a comprehensive systems engineering. Implementation of the reform of 
education and teaching, each step involves concepts, approaches, methods, and conditions of teachers, students, administration, and many other areas. We organize learning and research and the research group discuss and argue a lot of times. The architecture of applied talent training model is innovated based on unity of awareness-raising, educational philosophy-renewed and in-depth teaching practice in mechanical engineering.

\section{Determine Training Objectives}

Training objective is the core of talent training mode. After times of seriously research and argument we clearly proposed that "this profession trains application type senior engineering technology talent who adapted china social development and economic construction need, intellectual, moral and physical full development, acquire basic theory and knowledge of mechanical design, mechanical manufacturing, mechanical electronic and the automation accept modern mechanical engineers of basic training, has innovation spirit and engineering practice basic capacity, adapted mechanical engineering field development. "

Thus develop specifications as follows: the base is knowledge-acquired, the core is abilitycultivated, the coordinated development of knowledge, ability and quality. To solid foundation, focus on capacity, strengthen practice, and meet the team, compliance law, excellent foreign language. To strengthen the expanding and deepening of the knowledge structure of talents and personality development.

\section{Update the Idea of Education and Teaching}

Philosophy of modern knowledge structure. Modern mechanical discipline base are interdisciplinary and integration of mechanical engineering, mechanics and control science and engineering. Development and change of connotation also updates the knowledge of mechanical systems infrastructure. Mechanical design, mechanical manufacturing, mechatronics and automation are as the basic elements, capturing broad and solid basic knowledge are as base, focusing on engineering practical ability training, pay attention to the harmonious development of knowledge, ability, quality, focusing on development of the individualized characters.

Philosophy of engineering education. Focus on engineering practice ability and innovative consciousness must be oriented by social demand, engineering as the main line, optimization and integration of talent's knowledge structure. Need to reform the theory and practice of teaching content, teaching methods and means of organization, knowledge, engineering education. Enable the students to master the basic skills of modern mechanical engineer, working knowledge and application of technology, master the ability to discover and solve engineering problems.

The service concept of the teachers' leading role. In the teaching process, the epistemological status of teachers is "third party" and the role is "leading". Guide and instruct students effectively understand and acquire knowledge and skills. Making "Teaching" into "learning" and improving the quality of talent cultivation are the leitmotif of the teaching reform. In the teaching process, the teachers should service strive for the growth and development of students'.

\section{Optimize the Curriculum System}

Curriculum system is the "big picture" of comprehensive knowledge structure, is the foundation and key of creative personnel training. According to the training location, adapt to the development and popularization of new requirements in the field of education and employment. Optimization and integration are based on the basis of the original system. Now new system consists of four basic function modules general education courses, courses, integrated practice and competency training.

General education curriculum module. It is set to train common requirements of high-quality talents and promote quality-oriented education. It is made up of two parts of comprehensive quality and ability. 
Course modules. To cultivate senior engineering and technical personnel, to master general scientific knowledge and mechanical design, manufacturing, automation, such as basic theories and basic knowledge of the system requirements, to train theory and practice ability and innovative consciousness and continue learning. It consists six parts of engineering, mechanical design, mechanical manufacturing, mechanical and electronic automation, testing and quality control, the application of information.

Integrated practice modules. To cultivate applied talents. To implement basic training of modern mechanical engineers to meet mechanical engineering practical ability requirements. Introduction of practical projects, integrated teaching links of professional practice including theoretical teaching, experiment teaching and comprehensive design. To foster discovery, lay the foundation of analysis solving skills on engineering problem. It consists of five parts of comprehensive quality, comprehensive design of experimental courses, curriculum, professional practice and graduation design.

\section{Strengthen the Practice Teaching System}

Practical teaching system is an important part of the curriculum system. For the concrete implementation of engineering education philosophy, enhance the basic training of engineering practice, better engineering environment to create and organize the implementation. To restructure and consolidation on the basis of the original system. The new system consists of eight parts of the comprehensive quality, experimental courses, courses on experiments, curriculum links, integrated design curriculum, professional practice, graduation design, quality training.

Practice of comprehensive qualities. With the combination of ideological and political theory course and cultivation of students' ideological and ethical, legal, social responsibility, social skills and other aspects of quality.

Experimental course. Enable students to master the basic methods and skills of engineering in General.

Course experiments link. Making students know rich theoretical knowledge and master the basic methods and skills during the process of verifying theories and feeling in the course of practical knowledge. Making students improve the comprehensive abilities in using knowledge and engineering in comprehensive and design experiment in the process.

Computer experiments link. Enable students to master the basics of computers and information technology, using AutoCAD, Pro/E, MasterCAM and other application software to perform machinery products and parts design, manufacturing, simulation and other skills.

Integrated design curriculum. Optimize the original independent courses design and big assignment as required courses. Cultivating students' comprehensive analysis and design capabilities in using professional knowledge, standards and norms, to develop mechanical products, parts, technology, fixtures, mechanical and electrical systems, control systems, etc.

Professional practice. Making students direct experience in engineering field environment, master and improve the CAD drawing, machine operator, CNC machining operations infrastructure.

Graduation thesis. To cultivate students use the theory, methods and means, active discovery, analysis and solving skills on engineering problem, formation of systems design awareness in financial knowledge, technology, economy, environment, market, management and further enhance the creative awareness and ability.

\section{Innovate the Teaching Organization}

Application type talent training requires the University to break traditional teaching organization and teaching method, break traditional teaching form, which is teachers for led, and taught conclusion knowledge. Focusing on interactive teaching, and illuminating, and targeted, makes students has more strong of observation, expression, thought debate, innovation, language and computer skills, to adapted economic social development on talent quality of needs. 
Vigorously promote the elicitation, interactive, case type, the situational teaching. The case method according to Chinese students' characteristics in professional course teaching is popular with students. Specially built a special classroom in order to meet the needs of teaching and teaching methods innovation. Semicircular case interactive classrooms, providing situational teaching of enterprise culture classroom, small seminar rooms with small seminar activities, etc.

For practical and efficient to carry out practice teaching, improve the practical teaching system in our department, and strengthen the cultivation of students' practical ability and creativity, we actively reached with the well-known enterprises and institutions, promoting cooperation between schools and enterprises. Now we have built more than 20 practice base, providing students with a good training conditions, and many students become employees of practice base because of outstanding performance.

\section{Train and Retain A Faculty}

Introduction of subject leaders and teachers. Converging high academic levels and high levels of teaching and research professionals. The faculty building structure is to meet demand in quantity, reasonable structure in job title, qualifications, professional orientation, age, learning, high quality, the strong momentum of development.

Actively carry out research, teaching reform. Teaching is the center of all the work in the university, is the nature of teachers' work, is the ultimate goal of all work. To promote and nurture teaching and research, drive and improve teaching. Using academic research to improve teaching skills, using lateral to improve the ability of engineering practice, using teaching reform to improve teaching ability, so as to improve teachers' ability of innovative education.

Emphasis on improve training of teachers' ability. Encourage teachers to engage in the enterprise' scientific and technological research, technical service, teaching research and practice to improve themselves at their part-time. Promote the effectiveness of doctor-enterprise project. Support young teachers to $\mathrm{PhD}$ study. Support and sends the teachers to study overseas. Selected teachers to participate in a variety of educational sessions, conferences and training. Selecting business part-time teachers to join the education process as an auxiliary teacher, gradually forming faculty of school and enterprise integration.

\section{Application Effectiveness of the Personnel Training Mode}

After recent years of exploration and practice, school of mechanical engineering achieved some measure of success in application-oriented talents cultivation. Straighten out the relationship between scientific research, teaching research and teaching work. The three aspects need each other. Academic research promotes and nurtures teaching, teaching research guides and promotes teaching, improve the quality of teaching is the ultimate goal. Mechanical engineering students in recent years approved 20 innovation practical training program projects, including 8 national level, 12 provinciallevel. Students published 12 papers as first author, authorized 10 invention patents on the cooperation between teachers and students, 4 utility model patents, trial production project prototype, development of test-bed, produce a variety of forms of transmission, innovation prototype, complex geometry, etc. Restructuring and the formation of a students' multiple groups after school: underwater robot (robot fish) team, the innovation team, 3D digital design team, humanoid robot team, mechanical creative design team. The students achieve outstanding results in academic competitions in the national and provincial. They have achieved first prize, second prize, and third prize certificate for a total of 32 in 2015.

Our experience in application-oriented talents cultivation received much attention from domestic other institutes. We have received dozens visit of other college leadership from inside and outside the province, introduce and promote exploration and practical experience in talents' training. 


\section{Conclusion}

Teaching is the main melody of college work. Improvement and optimization of innovative talent training mode is a long-term, permanent jobs. Under the guidance of advanced education and teaching, the application to senior engineering and technical personnel training goal as a starting point, based on the teacher's level and capacity, optimize and constructing teaching system, train and retain a faculty, full use of the conditions and creating the necessary conditions for concrete measures of teaching reform of practice education. Our practice is still in the preliminary stages, the scientism and feasibility of many concrete reform measures need to continue to study and practice, need to constantly sum up experience and lessons learned. We believe that active efforts to create teaching and education ideas, faculty, experiment and training in school, practice base outside school, business conditions such as part-time teachers to promote the implementation of innovative architecture, deepen the reform of education and teaching, refine and implement concrete measures. This must improve the teaching quality and cultivate creative talent will show more results.

\section{Acknowledgment}

This research is supported by the teaching reform and research project of Suzhou University of Science and Technology in 2015 (2015JGM-20).

\section{References}

[1] Felse, Industry practice training through modular classroom exercises, Proc. 120th ASEE Annual Conf. and Exposition, (2013) 223-227.

[2] S.D. Formaneck and B.P. Cozzarin, Technology adoption and training practices as a constrained shortest pathproblem, Omega, 41(2013) 459-472.

[3] Hailey, M. Drysdale and D. Householder, The interest of mechanical engineering students in the grandchallenges for engineering in the 21st century, Proc. ASME 2011 Inter. Mechanical Engng. Congress and Exposition, (2011) 183-190.

[4] A.J. Rothkopf, To innovate, educate, Issues in Science and Technol., 26(2010) 88-106.

[5] R. Ramachandran, Enabling dispersed innovation-how the United States can utilize its long tail of talent, Inter. J.of Innovation and Technol. Manage. 9(2012) 7-30.

[6] N. Veurink and S.A.Sorby, Comparison of spatial skills of students entering different engineering majors, Engng Design Graphics J., 76(2012) 49-54.

[7] R. Wang and J.Xu, Exploration and practice of constructing MIS course experiment based on college-enterprisecooperation, Research and Exploration in Laboratory, 30 (2011) 104-106.

[8] Y.S.Lee, J. Gero and C.B.Williams, Comparing the design cognition of two engineering majors: ameasurement-based approach, Proc. ASME Design Engng. Technical Conf., (2012)111-119.

[9] Z.H. Li, Construction and practice on the training model of applied talents of mechanical engineering, J. of Changchun University of Science and Technol, 24(2011) 122-124.

[10]Z.J. Zhang, Analysis on outstanding engineering cultivation in high engineering education, Heilongjiang Researches on Higher Education, 12(2010) 140-141. 